\title{
Microbial Production of Antimicrobial Agents
}

\author{
Bassma H. Elwakil ${ }^{\text {* }}$, Mahmoud M. Abdelaziz ${ }^{2}$, Kareem M. Mahgoub ${ }^{2}$, \\ Ahmed M. Abdelrasheed ${ }^{2}$, Ahmed N. Ameen ${ }^{2}$ and Zakia A. Olama ${ }^{2}$ \\ ${ }^{1}$ Department of Allied Medical Science, Pharos University in Alexandria, Egypt \\ ${ }^{2}$ Department of Botany and Microbiology, Faculty of Science, Alexandria, Egypt
}

\begin{tabular}{|l|}
\hline Ke y w or d s \\
$\begin{array}{l}\text { Pentadecanoic acid, } \\
\text { 14-methyl- methyl } \\
\text { ester, Hexadecanoic } \\
\text { acid }\end{array}$ \\
\hline Article Info \\
\hline $\begin{array}{l}\text { Accepted: } \\
12 \text { November } 2019 \\
\text { Available Online: } \\
10 \text { December } 2019\end{array}$ \\
\hline \hline
\end{tabular}

Keywords

Pentadecanoic acid, 14-methyl- methyl ester, Hexadecanoic

Accepted:

12 November 2019 vailable Online:

\section{A B S T R A C T}

In a trial to search for a new antibiotic producer a terrestrial actinomycete was isolated from AL-alameen soil which proved to be a potential candidate for the production of active metabolites against E. coli 25922 and Staphylococcus aureus 25923. It was identified phenotypicallyas Streptomyces sp. The optimum activity was obtained when the organism was grown on glycerol as a sole carbon source at $30^{\circ} \mathrm{C}$ and $\mathrm{pH} 7.0$ for 192 $\mathrm{h}$. The highest metabolic activity noticed intracellulary and it was approved with MIC values. In a trial to test the combined activity of the extract and some antibiotics; synergistic action was noticed with ceftriaxone. Further investigations were applied to the extract for its active components using TLC and GC-MS which indicated that Pentadecanoic acid, 14-methyl-, methyl ester; Hexadecanoic acid, methyl ester and 2,4-bis(1,1dimethylethyl)- Phenol were the potent active components. Toxicity test will be evaluated for the active components as well as the crude extract.

\section{Introduction}

Antibiotics are one of the most important weapons in fighting bacterial infections and have greatly benefited the health-related quality of human life since their introduction. However, over the past few decades these health benefits are under threat as many commonly used antibiotics have become less and less effective against certain illnesses not only because many of them produce toxic reactions but also due to emergence of drug resistant bacteria. Resistance development is an even bigger problem since the bacterial resistance is often not restricted to the specific antibiotic prescribed, but generally extends to other compounds of the same class. Bacterial resistance and its rapid increase is a major concern of global public health and are emerging as one of the most significant challenges to human health. Treating bacterial infections by antibiotics is beneficial but their 
indiscriminate use has led to an alarming resistance among microorganisms as well as led to re-emergence of old infectious diseases (Sumitra and Kalpna, 2011). To add to this, there has been a considerable decrease in the rate of discovery of natural bioactive compounds. Therefore, intensive search for new antibiotics is needed on a worldwide basis. Actinomycetes have been especially useful to the pharmaceutical industry for their seemingly unlimited capacity to produce secondary metabolites with diverse chemical structures and biological activities (Thumar et al., 2010). Actinomycetes are mostly soildwelling organisms of great abundance and ecological important that produce an array of secondary metabolites, many of which have specific antibacterial or antifungal properties.

Actinomycetes are recognized as a separate group of organisms, are distinct from bacteria and fungi. With the discovery of actinomycin and streptomycin in 1940s by S.A Waksman, thousands of antibiotics were reported from various genera of actinomycetes. Production of secondary metabolites through fermentation is influenced by various environmental factors including nutrients, growth rate, feedback control, enzyme inactivation and variable conditions (oxygen supply, temperature, light and $\mathrm{pH}$ ) (Lin et al., 2010). In addition, production of valuable metabolites by actinomycetes differs qualitatively and quantitatively depending on the strains used in fermentation.

As one of the most significant components in the medium, carbon source plays a critical role as sources of precursors and energies for synthesis of biomass building blocks and secondary metabolite production. Therefore, influences of medium components and environmental conditions are an initial and important step to improve metabolite production of the genus Streptomyces (Wang et al., 2010).
The aim of the present work was to isolate an antibiotic producer from Egyptian environment for large scale production of antibiotic to be used in pharmaceutical industries.

\section{Materials and Methods}

\section{Soil Sampling}

Samples were collected from El-alameen soil areas. Soil samples were collected aseptically from different sites using standard methods. The collected samples were transferred to research laboratory of Microbiology, Department of Microbiology and Botany, where the entire research work was carried out. The soil samples were sieved and from each sample, $1 \mathrm{~g}$ of soil sample was then added in different test tubes containing $10 \mathrm{~mL}$ physiological saline $(\mathrm{NaCl}, 8.5 \mathrm{~g} / \mathrm{L})$ and shaken well using vortex mixer. These test tubes were considered as stock solution (Abebe et al., 2013).

\section{Isolation of Actinomycetes}

From the stock solution, a volume of $1 \mathrm{~mL}$ was transferred aseptically and added to a test tube containing $9 \mathrm{~mL}$ of sterile physiological saline and mixed well. From this test tube, 1 $\mathrm{mL}$ of aliquot was again transferred and mixed with another $9 \mathrm{~mL}$ of sterile physiological saline to make $10^{-2}$ dilution factor. Similarly, dilutions up to $10^{-5}$ were made using serial dilution technique for all soil samples. A volume of $1 \mathrm{~mL}$ of suspension from $10^{-4}$ and $10^{-5}$ serially diluted tubes were taken and spread evenly with sterile L-shaped glass rod over the surface of sterile starch casein agar plates aseptically using spread plating technique. Amoxicillin $(20 \mu \mathrm{g} / \mathrm{mL})$ and cyclohexamide $(25 \mu \mathrm{g} / \mathrm{mL})$ were added in the prepared media to inhibit bacterial and fungal contamination, respectively. The plates were incubated aerobically at $30{ }^{\circ} \mathrm{C}$ up to $7 \mathrm{~d}$ and 
observed intermittently during incubation (Abebe et al., 2013).

\section{Purification of Actinomycetes}

After incubation, the grown actinomycetesin the plates were identified based on color, dryness, rough, convex colony. The identified colonies were purified by repeated streak plate method. The isolated colonies were identified and transferred to GYM (Glucose, Yeast Malt extract medium) slant and preserved at $4^{\circ} \mathrm{C}$. These cultures were used for further study (Reddy et al., 2011).

\section{Screening for an Antibiotic Producer}

Preliminary screening of antibiotic producing strains against ATCC organisms was done by cross-streak method.

The isolated actinomycete strain was crossstreaked on GYM medium and incubated for 5 days. After incubation, overnight culture of test organisms. Escherichia coli 25922, Pseudomonas aeruginosa 27853, Klebsiella pneumonia 13883, Staphylococcus aureus 25923 and Staphylococcus epidermidis 12228; were streaked against the isolated actinomycete strain. The plates were incubated at $37^{\circ} \mathrm{C}$ for overnight. After incubation screened antagonistic activity of actionomycete against the organisms was detected (Williams et al., 1983).

\section{Identification of Actinomycetes}

\section{Phenotypic characterization}

The isolated actinomycetes colonies were observed under high power magnifying lens. The colony morphology with respect to color, aerial mycelium, size and nature of colony and reverse side color were observed and identified (Pandey et al., 2008).

\section{Biochemical characterization}

Amylase production, gelatin hydrolysis, casein hydrolysis, urea hydrolysis and citrate utilization were tested according to Cross and William (1971). Degradation of esculin test was done according to the method of Gordon et al., (1974). Nitrate reduction test was done according to the method of Gordon (1966). Hydrogen sulfide production and oxidase test were done according to the method of Cowan (1974).

\section{Microscopic observation}

Gram staining can be used to make slides of bacteria and Actinomycetes.

\section{Scanning electron microscope}

The sterile GYM agar plates were prepared and the respective cultures were swabbed on the medium and inserted 3-4 sterile square cover slips at an angle $45^{\circ}$ and incubated at $30^{\circ} \mathrm{C}$ for 8-10 days. After incubation, the cover slips were carefully removed. The morphological characters were observed and identified (Tiwari, 2009).

Optimization of the environmental and nutritional factors affecting the biosynthesis of the antimicrobial agent

The optimization of the environmental and nutritional factors tested in the present work namely:carbon source, incubation period, $\mathrm{pH}$ values, and incubation temperatures; each were evaluated using one factor at a time. The influence of the parameters in different growth culture conditions was assessed in order to enhance the production of active metabolites during growth. Three carbon sources were used (starch, glycerol, and glucose one at a time) in $1 \%$ base medium $(0.03 \%$ casein, $0.2 \%$ $\mathrm{NaCl}, 0.2 \% \mathrm{~K}_{2} \mathrm{HPO}_{4}, 0.005 \% \mathrm{MgSO}_{4}, 0.002 \%$ $\left.\mathrm{CaCO}_{3}, 0.2 \% \mathrm{KNO}_{3}\right)$. After the determination 
of the optimal carbon source for the production of a crude extract that exhibited the best antimicrobial activity, the influence of incubation temperature was evaluated. Six temperatures were used $\left(20^{\circ} \mathrm{C}, 25^{\circ} \mathrm{C}, 30^{\circ} \mathrm{C}\right.$, $35^{\circ} \mathrm{C}, 40^{\circ} \mathrm{C}$, and $45^{\circ} \mathrm{C}$ ). After, ideal $\mathrm{pH}$ was established using $\mathrm{pH}$ values of 5.0, 6.0, 7.0, 8.0, 9.0 and10.0, $\mathrm{pH}$ values of the growth medium were adjusted. Incubation times for the production of active metabolite extract were also assessed every $24 \mathrm{~h}$ during the 10day incubation period (Tiele and Sueli, 2016).

\section{Growth curve}

A growth curve was constructed to evaluate growth time and correlate it with the production phase of the active metabolite extract. It was grown in submerged culture for ten days under the conditions described above as optimal for the production of active metabolite extract against the tested isolates. Every $24 \mathrm{~h}$ during the 10- day growth period 1 $\mathrm{ml}$ was separated and OD was evaluated(by absorbance at A580) (Tiele\&Sueli, 2016).

\section{Extraction of Intracellular antibacterial metabolite}

After incubation, the contents of the flasks were centrifuged at 7,000 rpm for $15 \mathrm{~min}$ and the cells obtained as pellet were lysed open using sonification. The sonicated cells obtained were treated with $50 \%(\mathrm{v} / \mathrm{v})$ ethanol by shaking at $120 \mathrm{rpm}$ for $1 \mathrm{~h}$ at $28^{\circ} \mathrm{C}$ for extraction of the antibiotic. The contents of the flask were again centrifuged at $7000 \mathrm{rpm}$ for 15 min (Akansha et al., 2013).

\section{Extraction of extracellular antibacterial metabolite}

To concentrate the antimicrobial metabolite produced from the isolates, equal volume of ethyl acetate was added in each fermented cultures for $1 \mathrm{~h}$ at $37{ }^{\circ} \mathrm{C}$. Then the ethyl acetate containing active metabolite was separated and used as stock concentration for determination of antimicrobial activity against test organisms using ethyl acetate as a control (Abebe et al., 2013 and Atta et al., 2010).

\section{Detection of the antibiotic activity}

Escherichia coli25922 and Staphylococcus aureus 25923 bacterial suspensions' was adjusted to 0.5 McFarland standard $\left(10^{8}\right.$ $\mathrm{CFU} / \mathrm{mL}$ ) and inoculated into on the surface of prepared Muller Hinton agar. Twenty micro liters of dissolved crude extract was loaded into each disc and left for $30 \mathrm{~min}$ until the metabolite was diffused. Then the plates were incubated for $24 \mathrm{~h}$ at $37{ }^{\circ} \mathrm{C}$. After incubation, the zone of inhibitions were measured and recorded.

\section{Minimum inhibitory concentration (MIC)}

Minimum inhibitory concentration (MIC) was determined using the micro-dilution method in broth, according to the standard method (M7A7 (CSLI 2006). Incubation took place at 35 ${ }^{\circ} \mathrm{C}$ for $24 \mathrm{~h}$ and $48 \mathrm{~h}$. MIC was defined as the lowest concentration of the crude extract able to inhibit bacterial growth (Tiele and Sueli, 2016).

Thin layer chromatography analysis (TLC analysis)

The active metabolic extract of the actinomycete was spotted on a silica-gel TLC plate and developed with butanol:acetic acid:water $(4: 1: 5 \mathrm{v} / \mathrm{v})$. When half of the plate was developed, the solvent system was substituted with water (Harborne and Boardley, 1983), and developing was then reinitiated.

\section{GC-MS}

GC-MS analyses were carried out on a HP7890A GC system connected to a HP5975C mass selective detector fitted with a 
HP-5 fused silica capillary column $(30 \mathrm{~m}, 0.22$ $\mathrm{mm}$ i. d., $0.25 \mu \mathrm{m}$ film, Hewlett-Packard, Wilmington, USA). Conditions were as follows: inlet pressure: $67 \mathrm{kPa}, \mathrm{He} 23.3 \mathrm{~mL}$ min-1 ; injection volume $1 \mu \mathrm{L}$; injector $250^{\circ} \mathrm{C}$; transfer line $300^{\circ} \mathrm{C}$; electron energy $70 \mathrm{eV}$. The $\mathrm{GC}$ was programmed as follows: $50^{\circ} \mathrm{C}(5$ min isothermic), increasing at $5^{\circ} \mathrm{C}$ min-1 to $320^{\circ} \mathrm{C}$. Retention indices were determined from a homologous series of $\mathrm{n}$-alkanes (C8C32). The identification of compounds was performed by comparison of mass spectra to database spectra(Gerardo et al., 2013).

\section{Results and Discussion}

\section{Samplingand isolation of Actinomycetes}

In a trial to isolate antibiotic producers specially actinomycetes, different soil samples were tested for the presence of Actinomycetes grown on starch casein agar plates using spread plating technique. Amoxicillin (20 $\mu \mathrm{g} / \mathrm{mL})$ and cyclohexamide $(25 \mu \mathrm{g} / \mathrm{mL})$ were supplemented to the medium to inhibit bacterial and fungal contamination, respectively. Purification of Actinomycetes was made on a selective media namely GYM medium. Results indicated that one strain of Actinomycetes (AC) was detected and labeled as $\mathrm{AC} 1$.

\section{Screening of Antibiotic Producing Strains}

Preliminary screening of antibiotic producing strains against ATCC organisms was done by cross-streak method. The isolated actinomycete strain was cross-streaked over GYM medium and incubated for 5 days. Escherichia coli 25922, Pseudomonas aeruginosa 27853, Klebsiella pneumoniae 13883, Staphylococcus aureus 25923and Staphylococcus epidermidis 12228; were streaked against the isolated actinomycete (Figure 1). The plate was incubated at $37^{\circ} \mathrm{C}$ overnight. After incubation antagonistic activity of actionomycetes against the organisms was detected (Table 1) AC2 was subjected for further identification by phenotypical analysis. Actinomycetes are rounded shape, Gram positive bacteria (Figure 3 ), non-motile, white in color and substrate mycelium has a dark brown color (Figure 2).

The isolated actinomycete strain showed monoverticillus spore chain hyphae (Figure 4). But in order to identify the isolated strain of Actinomycetes; biochemical reactions tests were done according to International Streptomyces Project (ISP). The performed biochemical reactions indicate that the isolated strain is Streptomyces sp. (Table 2 and Figure $5)$. The cross-streak plate technique was used to screen the antibiotic producing Actinomycetes using Muller Hinton agar medium. Antibacterial activity was exhibited by $70 \%$ of the isolates. The lowest activity was exhibited by Gram negative bacteria $(30 \%)$. The putative isolates of primary screening when subjected to secondary screening showed different activity. Some showed the activity in the secondary screening while some showed less inhibition. The results of primary screening and secondary screening reveal that most of the active isolates were active against E. coli and Staphylococcus aureus. The reason for such differential sensitivity could be ascribed to the morphological differences in these microorganisms; According to Bhagabati et al., (2005) the Gram positive could be more susceptible as they have only an outer peptidoglycan layer which is not an effective permeability barrier. The present investigation was aimed to isolate Actinomycetes from the soil of El-Alameen. The soil contains a diversity community of organisms differentiated by cross-streak plate technique and antibacterial activity. To study the production of secondary metabolites, the isolates of Actinomycetes were inoculated into a suitable medium and morphological 
characters were studied by Gram staining. The isolates showed good sporulation, with compact chalky like dries colonies and spore arrangements relevant to that of Streptomyces (Thangapandian et al., 2007). The biochemical studies indicate that the Actinomycetes, isolate can be used a potent source for the enzymes like amylase and caseinase. The enzymes are very much useful for their saprophytic mode of life (Astalakshmi et al., 2014).

Factors effecting on the biosynthesis of the antimicrobial agent (optimization)

\section{Carbon source}

Glycerol was the optimum carbon source that leads to maximum antibiotic activity while other carbon source (glucose, starch) showed inferior results (Figure 6). These results show that the synthesis of active compounds by microorganisms is not steady and can be adjusted by modifying the culture conditions.

Previous studies analyzed the influence of different carbon sources, and discovered that a glucose medium favors the production of active metabolites (Al-Zahrani 2007).

\section{Temperature}

The optimum incubation temperature that leads to maximum activity was $30^{\circ} \mathrm{c}$ lower or higher temperatures showed inferior results (Figure 7). Confirming the findings in the literature (Elleuch et al., 2010), $30{ }^{\circ} \mathrm{C}$ was the ideal temperature to cultivate and to optimize the production of active metabolites since the extract produced, exhibited the highest antimicrobial activity.

\section{pH]}

The optimum $\mathrm{pH}$ that leads to maximum activity was 7.0. Lower or higher $\mathrm{pH}$ showed inferior results (Figure 8). $\mathrm{pH}$ is one of the most important parameters of culture media, as it directly influences activity of several enzymes that plays an essential role in the metabolism of microorganisms (Guimarães et al., 2004). This relationship was observed in the present study also.

\section{Incubation Time}

The optimum time that leaded to maximum activity was 8 days. Lower or higher time showed inferior results (Figure 9). Banga et al., (2008) analyzed the production of active metabolites by isolates of Streptomyces sp., observing that the maximum amount of antibiotics was produced by cultures grown for $96 \mathrm{~h}$.

\section{Growth curve}

The growth curve of the Streptomyces sp. under investigation revealed that the active metabolite is secondary metabolite as the activity appeared when the isolate enters the stationary phase (Figure 10).

According to Bibb (2005), the limited nutrient availability during steady-state growth promotes the formation of secondary metabolites that are required for microorganism survival.

\section{Detection of the intracellular and extracellular antimicrobial agent}

The antibacterial activities were studied by disc diffusion method for both intracellular and extracellular metabolic extract.

The internal metabolic extract of Actinomycetes isolate showed high antibacterial activity against the tested organisms (Figure 11 and Table 3). Zakir et al., (2002) stated that the external extract showed strong activity against E. coli (13 $\mathrm{mm})$, B. subtilis $(12 \mathrm{~mm})$, Salmonella typhi (12 mm). 
Table.1 Antibacterial Activity of isolated actinomycetes

\begin{tabular}{|c|c|}
\hline ATCC Organisms & *Antibacterial activity of AC \\
\hline E. coli 25922 & ++ \\
\hline Klebsiella pneumoniae 13883 & - \\
\hline Pseudomonas aeruginosa 27853 & - \\
\hline Staphylococcus aureus 25923 & ++ \\
\hline Staphylococcus epidermidis 12228 & + \\
\hline
\end{tabular}

Table.2 Biochemical characteristic of the isolate

\begin{tabular}{|c|c|}
\hline Parameter & Result \\
\hline Starch hydrolysis & Positive \\
\hline Casein hydrolysis & Positive \\
\hline Blood hydrolysis & Positive \\
\hline Catalase production & Positive \\
\hline Oxidase production & Positive \\
\hline Urease production & Positive \\
\hline Hydrogen sulfide production & Positive \\
\hline Nitrate reduction & Negative \\
\hline Gelatin liquefaction & Negative \\
\hline Methyl red test & Negative \\
\hline Voges-proskaur test & Negative \\
\hline Indole production & Negative \\
\hline Citrate utilization & Positive \\
\hline Bile esculin degradation & Positive \\
\hline
\end{tabular}

Table.3 Extra and intracellular antibiotic activity against ATCC strains expressed as inhibition zone (mm)

\begin{tabular}{|c|c|c|}
\hline \multirow{2}{*}{ Test organism } & \multicolumn{2}{|c|}{ Inhibition zone $\mathbf{( m m )}$} \\
\cline { 2 - 3 } & $\begin{array}{c}\text { Intracellular } \\
\text { extract }\end{array}$ & $\begin{array}{c}\text { Extracellular } \\
\text { extract }\end{array}$ \\
\hline E. coli $\mathbf{2 5 9 2 2}$ & 17 & 10 \\
\hline S. aureus $\mathbf{2 5 9 2 3}$ & 14 & 6 \\
\hline
\end{tabular}

Table.4 MIC of internal and external metabolic extract

\begin{tabular}{|ccc|}
\hline Test organism & $\begin{array}{c}\text { Intracellular extract } \\
(\mathrm{mg} / \mathrm{ml})\end{array}$ & $\begin{array}{c}\text { Extracellular extract } \\
(\mathrm{mg} / \mathrm{ml})\end{array}$ \\
\hline E. coli $\mathbf{2 5 9 2 2}$ & 32 & 128 \\
\hline S. aureus 25923 & 64 & 128 \\
\hline
\end{tabular}


Fig.1 Antibacterial activity of Actinomycetes.
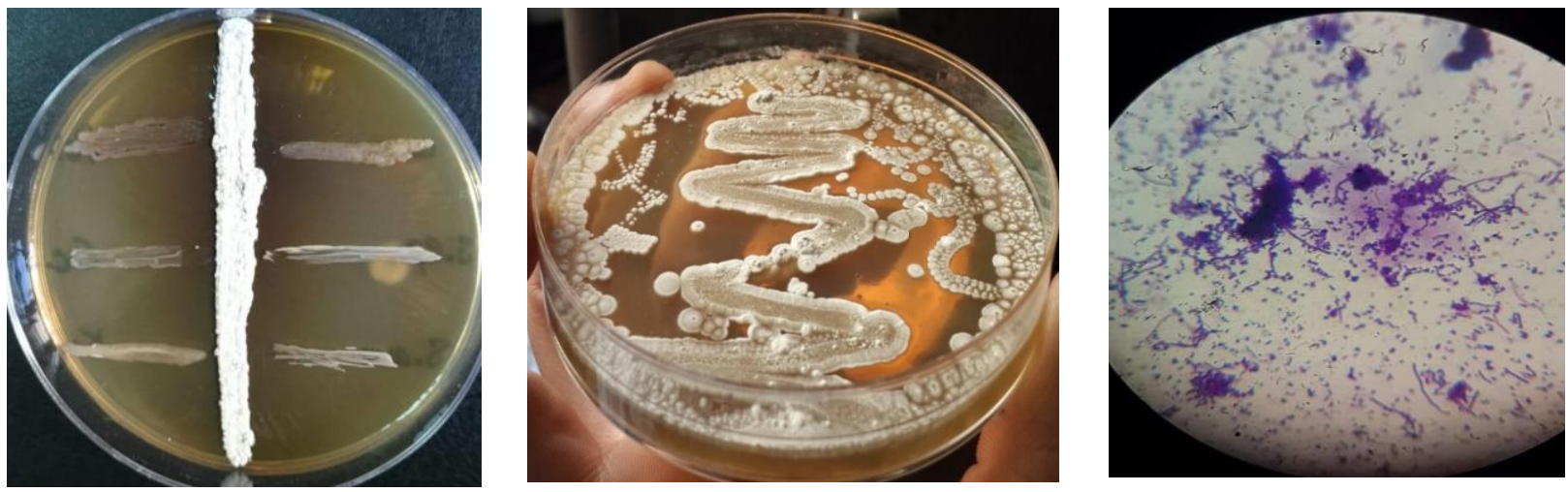

Fig.4 SEM of the Streptomyces sp.

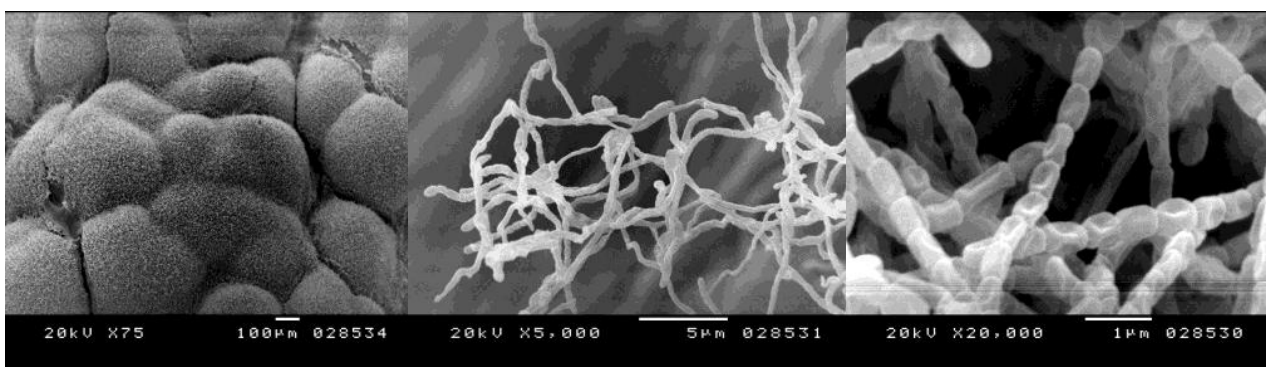

Fig.5 Actinomycetes Isolate Grown on different substrates and biochemical reactions.(A) Blood hydrolysis, (B) Starch hydrolysis, (C) Sabouraud dextrose agar, (D) VP, Nitrate, MIO, MR, Citrate and Urease biochemical tests (E) Bile esculin degradation (F) Gelatin liquefaction

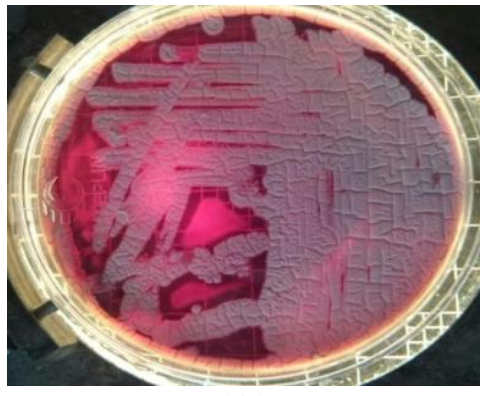

(A)

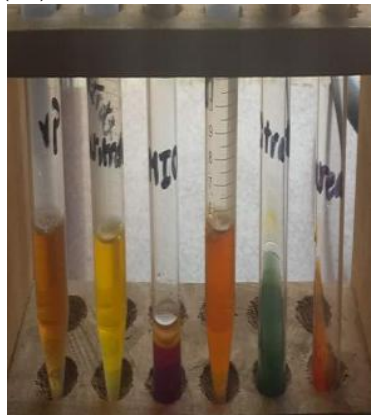

(D)

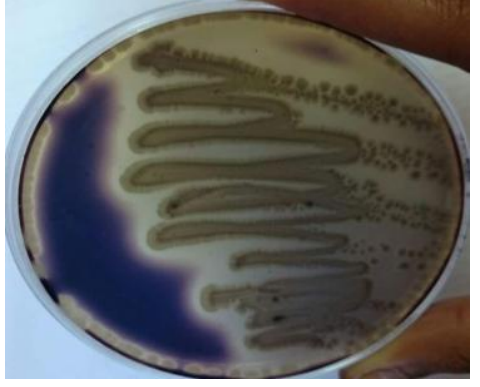

(B)

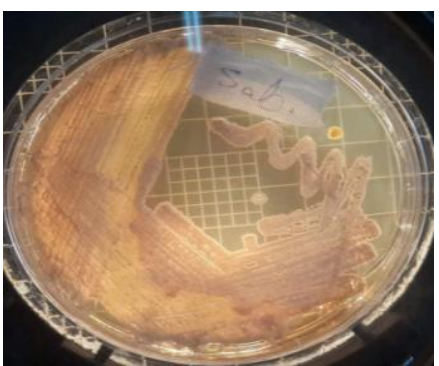

(C)

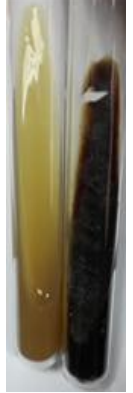

(E)

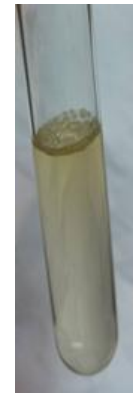

(F) 
Fig.6 Streptomyces sp. Antibiotic activity as affected by different carbon source

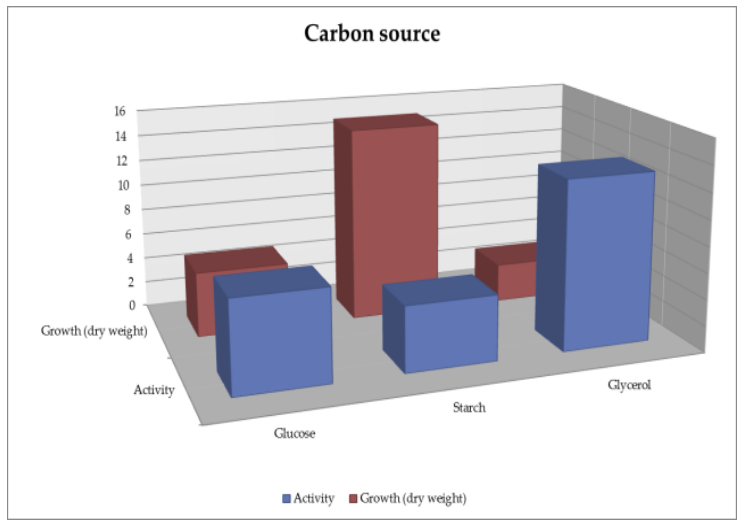

Fig.7 Streptomyces sp. Antibiotic activity as affected by incubation temperature

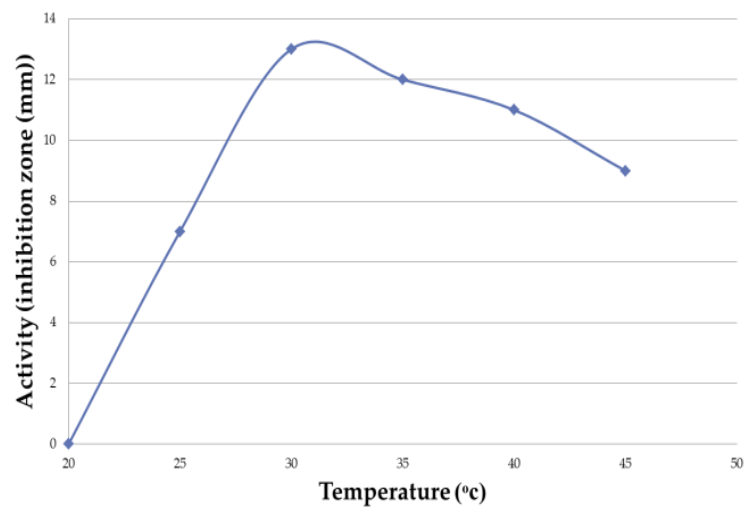

Fig.8 Streptomyces sp. Antibiotic activity as affected by initial $\mathrm{pH}$

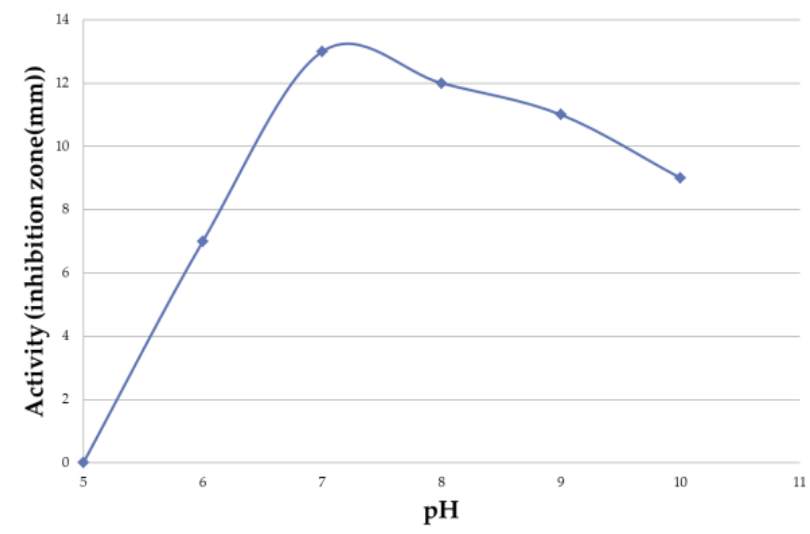


Fig.9 Streptomyces sp. Antibiotic activity as affected by incubation time

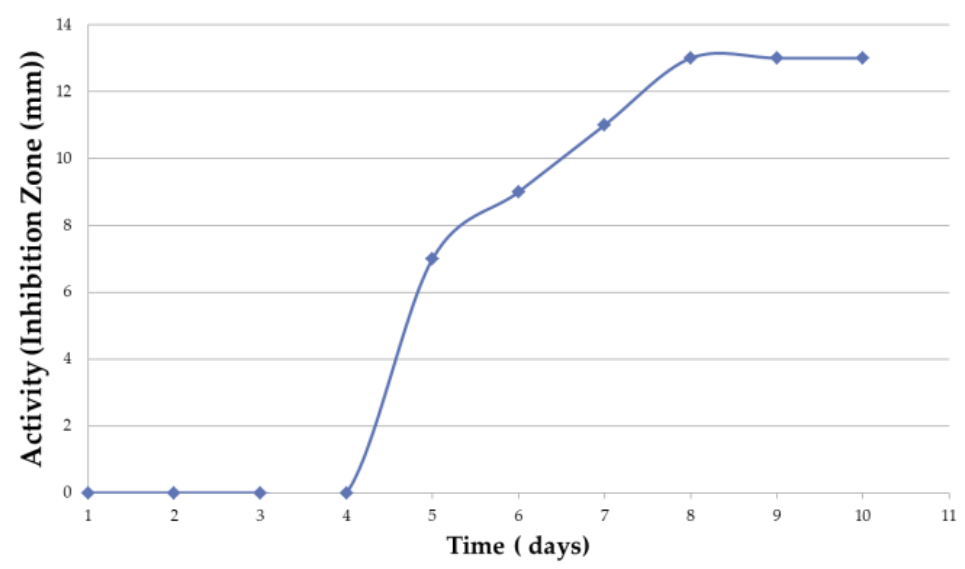

Fig.10 Growth curve of Streptomyces sp

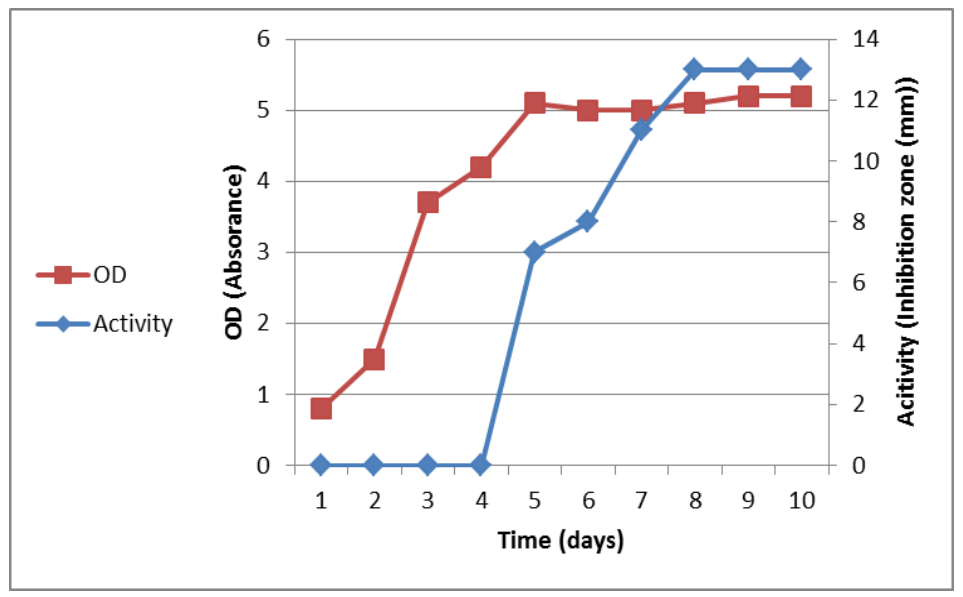

Fig.11 Disc diffusion method (A) intracellular extract and (B) extracellular extract

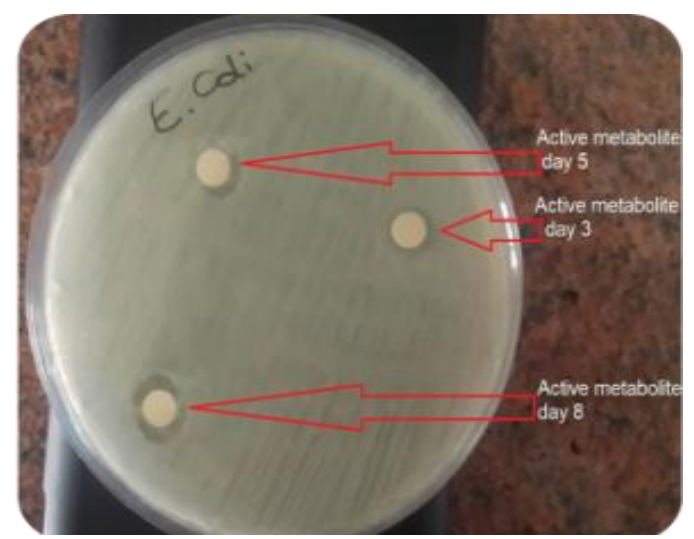

(A)

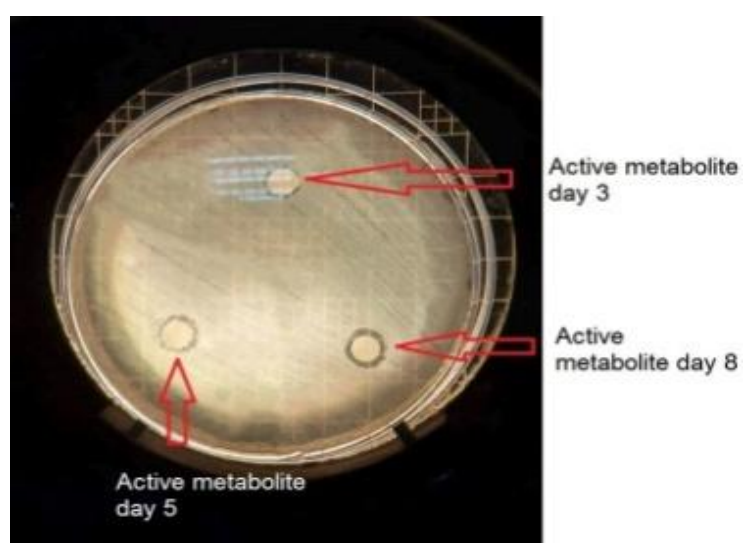

(B) 
Fig.12 Synergistic effect with the antibiotic

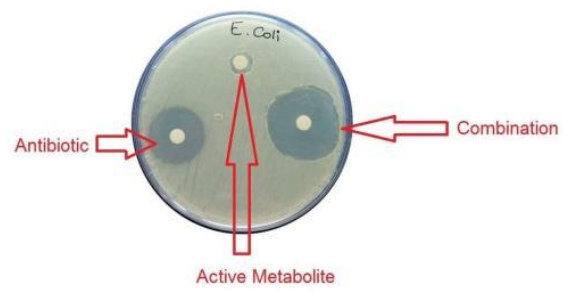

Fig.13 TLC of the extract

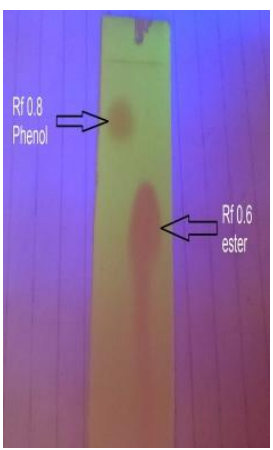

Fig.14 GC-MS chromatogram

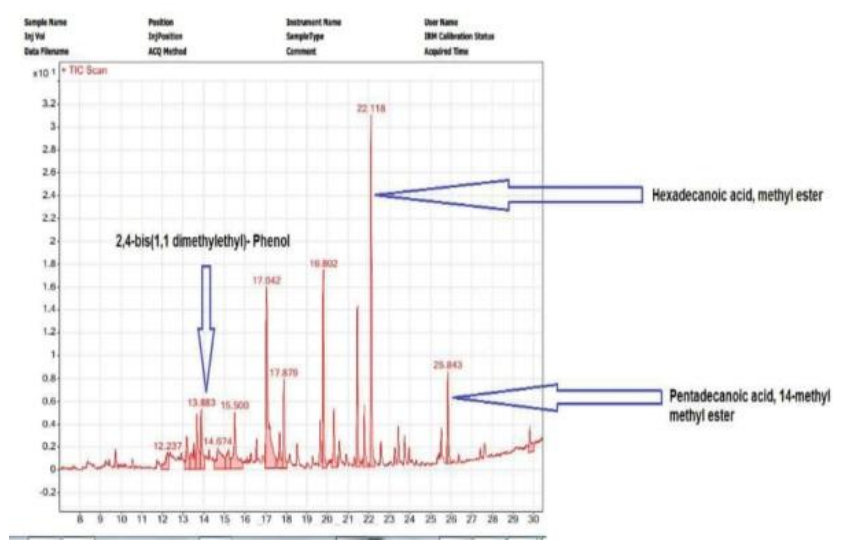

Minimum inhibitory concentration (MIC)

In a trial to detect the MICs for both intracellular and extracellular metabolites it was revealed that the intracellular metabolite extract concentration was 32 and $64 \mu \mathrm{g} / \mathrm{ml}$ against E. coli 25922 and S. aureus 25923, respectively.
But in case of extracellular metabolite extract there was no difference between the MIC values between the tested isolates $(128 \mu \mathrm{g} / \mathrm{ml})$ (Table 4).

\section{Combination with known antibiotics}

Combination therapy or synergistic therapy; against resistant microorganisms may lead to 
new ways of treating infectious diseases and probably this represents a potential area for further future investigations. Combination therapy is helpful and useful for patients with serious infections caused by drug resistant pathogens.

In our trial, Ceftriaxone $(30 \quad \mu \quad \mathrm{g})$ and Ampicillin sulbactam $(20 \mu \mathrm{g})$ were tested in combination with the actinomycete extract. Synergistic action was noticed between the ceftriaxone antibiotic and the extract (Figure 12).

Thin layer chromatography analysis (TLC analysis)

The internal metabolic extract of the actinomycete was spotted on a silica-gel TLC plate and developed with butanol:acetic acid:water $(4: 1: 5, \mathrm{v} / \mathrm{v})$. When half of the plate was developed, the solvent system was substituted with water (Harborne, 1998), and developing was then reinitiated. TLC analysis showed two spots identified as esters (Rf 0.6) and phenol (Rf 0.8) (Figure 13).

\section{Gas chromatography-mass spectrometry analyses}

The components present in the intracellular metabolic extract were characterized and three compounds were clearly defined in the chromatogram (Figure 14). Pentadecanoic acid, 14-methyl-, methyl ester (5.8\%); Hexadecanoic acid, methyl ester (19.3\%) and 2,4-bis(1,1 dimethylethyl)- Phenol (1.16\%) were found to be the potent active fractions in the crude extract and are known for their antibacterial activity.

Mechanism of antibacterial action of natural products may have been proposed with a hypothesis which involve: hydrophobic and hydrogen bonding of phenolic compounds to membrane proteins, followed by partition in the lipid bilayer; perturbation of membrane permeability consequent to its expansion and increased fluidity causing the inhibition of membrane embedded enzymes; membrane disruption; destruction of electrons transport systems and cell wall perturbation (Odhav et al., 2002).

The results of the present investigation concluded that the isolated actinomycete under test could be used as a good candidate for antibiotic production on large scale industry that can be applied in pharmaceutical industry specially the active component that was fractionated from the crude product. On the top of that it can be used in combination with ceftriaxone and leads to duplication of the activity and so lowering the antibiotic dose and reducing its toxic effect and avoiding the emergence of resistance with a safer option and with advantage of reducing the price to half.

\section{Acknowledgments}

We would like to express our gratitude thanks M.M. Abdelaziz, K.M. Mahgoub, A.M. Abdelrasheed and A.N. Ameen Microbiology lab technicians for their help.

\section{References}

Abebe B., Feleke M. and Berhanu A. (2013).Isolation and screening of antibiotic producing actinomycetes from soils in Gondar town, North West Ethiopia. Asian Pac J Trop Dis. 3(5): 375-381.

Akansha S., Ramraj U., Dhaneshwar K. and Naveen K. (2013).Antifungal activity of soil Actinomycetes. J Sci. Ind. Res. 491(72): 491-497.

AL-Zahrani S.H.M. (2007). Studies of the antimicrobial activityof Streptomyces sp. isolated from Jazan. J King AbdulazizUniSci 19: 127-138. 
Astalakshmi A., Thangapandian V. and Lingakumar K. (2014).Isolation and Characterization of Actinomycetes from the Soil of Devathanam - A Foot-hill of Western Ghats.Int. J Pharma. Res. Rev. 3(1):15-20.

Atta H.M., El-Sehrawi M.H., Awny N.M. and El-Mesady N.I., (2011).Cirramycin-B antibiotic production by Streptomyces Cyaneus-AZ-13Zc: fermentation, purification and biological activities. New York Sci. J. 4(2): 35-42.

Banga J, Praveen V, Singh VI, Tripathi CKM andBihari V. (2008).Studies on medium optimization for theproduction of antifungal and antibacterial antibiotics from a bioactive soil actinomycete. Med. Chem. Res. 17: 425-436.

Bhagabati P., Prakash G. andAgrawal V.P. (2005). Studies on the antibacterial activity of the Actinomycetes isolated from the Khumbu Region of Nepal. Academician of Royal Nepal Academy of Science and Technology.

Bibb M.J. (2005).Regulation of secondary metabolism in Streptomycetes. Curr.Opin.Microbiol. 8: 208-215.

Cross T. and William S.T. (1971). Actinomycetes. In: Method in microbiology. 4th ed. London: Academic press. Pp. 29-65.

Elleuch L, Shaaban M, Smaoui S, Mellouli L,Karray-rebai I, Fguira LF, Shaaban KA and Laatsch H. (2010). Bioactive secondary metabolites from a new terrestrial Streptomyces sp. TN262.ApplBiochemBiotechnol. 162: 579-593.

Gerardo R., Elda C. and Ernesto G. (2013). Avocado roots treated with salicylic acid produce phenol-2,4-bis (1,1dimethylethyl), a compound with antifungal activity. J. Plant Phys. PLPH-51775; 1-10.

Gordon R.E. (1966). Some criteria for the recognition of Nocardia madura (Vincent) blanchord. J. General Microbiol. 45: 355-364.

Gordon R.E., Barnett D.A., Handehan J.E. and Pang C.H., (1974). Nocardia coeliaca, Nocardia autotrophica and Nocardia Strain. Int.J. Syst. Bacteriol. 24: 5463.

Guimarães L.M., Furlan R.L.A., Garrido L.M., VenturaA., Padilla G. and Facciotti M.C.R. (2004).Effect of pH on the production of the antitumor antibiotic retamycin by Streptomyces olindensis. Biotechnol Appl. Biochem. 40:107-111.

Harborne J.B. and Boardley M., (1983). Identification of two gossypetinmonomethyl ethers as yellow flower pigments in the Rutaceae. Z. Naturforsch. 38: 148-150.

Lin J., Bai L., Deng Z. and Zhong J.J. (2010). Effect of Ammonium in Medium on Ansamitocin P-3 Production by Actinosynnem apretiosum. Biotechnol. Biopro. Engineer., 15: 119-125.

Odhav B., Juglla S. and Govinden R. (2002). Spices oils for the control of cooccurring mycotoxins producing fungi. Euro. Food Res. Tech. 65: 683-687.

Pandey B., Ghimire P. and Agrawal V.P. (2008). Studies on the antimicrobial activity of the actinomycetes isolated from the Khumbu region of Nepal. Appl. Microbiol. 5: 235-261.

Sumitra C. and Kalpna R. (2011). Combination therapy: Synergism between natural plant extracts and antibiotics against infectious diseases. Sci. against micro. Path. Comm. current res. and tech. adv. A.M éndez Vilas (E.d) Formatex. Pp. 520-529.

Thangapandian V., Ponmurugan P. and Ponmurugan K. (2007). Actinomycetes diversity in the rhizosphere soils of different medicinal plants in Kolly Hills, Tamilnadu, India, for secondary 
metabolites. Asi J Plan. Sci. 6(1): 6670.

Thumar J.T., Dhulia K. and Singh SP. (2010). Isolation and partial purification of an antimicrobial agent from halotolerant alkaliphilic Streptomyces aburaviensis strain Kut-8. World J. Microbiol Biotechnol.(In press).

Tiele C. and Sueli V.D.S. (2016). Evaluation of antimicrobial activity of the endophytic actinomycete R18 (6) against multiresistant Gram-negative bacteria. Ann. Brazil Ac. Sci. 88(1): 155-163.

Tiwari K.D. (2009). Protocol for actinomycetes study in RLABB 2008/9. Tridhtuven University Tikiriupr: Central Department of Microbiology, Institution of Science and technology. p. 21.

Wang X., Huang L., Kang Z., Buchenauer H. and Gao X. (2010). Optimization of the Fermentation Process of Actinomycete Strain Hhs.015T. J. Biomed. Biotechnol. doi: 10.1155/2010/141876.

Williams ST, Goodfellow M, Wellington EMH, Vickers JC, Alderson G, Sneath PHA.(1983). A probability matrix for identification of Streptomyces. J Gen Microbiol. 129: 1815-1830.

Zakir S.M., Nazinin A., Khatune Z., Sultana S., Shah A., Bhuiyan G., Sadik M., Arteruzzaman C., Gopur M.A. and Rahman M.D. (2002). In vitro antibacterial activity of metabolites isolated from Streptomyces species. Biotechnol. 1(24): 100-106.

\section{How to cite this article:}

Bassma H. Elwakil, Mahmoud M. Abdelaziz, Kareem M. Mahgoub, Ahmed M. Abdelrasheed, Ahmed N. Ameen and Zakia A. Olama. 2019. Microbial Production of Antimicrobial Agents. Int.J.Curr.Microbiol.App.Sci. 8(12): 1439-1452. doi: https://doi.org/10.20546/ijcmas.2019.812.174 